\title{
Preparing nursing students for interprofessional learning
}

\author{
Jalina Karim ${ }^{1}$, Nabishah Mohamad ${ }^{1}$, John H.V. Gilbert ${ }^{2}$, Ismail Saibon ${ }^{1}$, Subahan T.Mohd \\ Meerah $^{3}$, Hamidah Hassan ${ }^{1}$, Harlina Halizah Siraj ${ }^{1}$ ' \\ ${ }^{1}$ Faculty of Medicine, Universiti Kebangsaan Malaysia, Jalan Yaacob Latif, 56000 Cheras, Kuala Lumpur, \\ ${ }^{2}$ College of Health Disciplines, University of British Columbia, ${ }^{3}$ Faculty of Education, Universiti Kebangsaan, \\ Bangi, Selangor.
}

\begin{tabular}{ll}
\hline ARTICLE INFO \\
Received & $: 24 / 10 / 2013$ \\
Accepted & $: 10 / 03 / 2014$ \\
Published & $: 01 / 06 / 2014$
\end{tabular}

KEYWORD

Interprofessional learning

Nursing student

Collaboration

Learning process

Student perception

\begin{abstract}
Introduction: Teaching strategies for nursing students need to be varied to prepare them for their future practice, and to increase their confidence levels in order to ensure that they deliver high quality care to patients. Interprofessional learning (IPL) is a way to develop health professional teams in that it facilitates collaboration by having health professional students learn with, from and about each other's roles and responsibilities in the provision of patient care. At present, nurses are unable to learn together with other health professional students during their clinical posting, because of professional barriers. Objective: To explore nursing students' knowledge and perception of interprofessional learning. Authors developed a grading system named the Discrepancy-Agreement. Method: This paper presents the results of a focus group discussion with nursing students $(n=8)$. A semi structured guide was used that focused on knowledge, experiences and benefit related to IPL. Result: Data were analysed, from which four major themes emerged: 1) Learning with, from and about other health professionals; 2) Communication skills; 3) Teamwork; and 4) Preparation of future practice Conclusion: The results of this study suggest IPL as an educational strategy should be introduced to nursing students in order to extend their understanding of the roles and responsibilities of other health professionals and to provide them with opportunities to work collaboratively with other health professionals.
\end{abstract}

(C) Medical Education Department, School of Medical Sciences, Universiti Sains Malaysia. All rights reserved.

CORRESPONDING AUTHOR: Jalina Karim, MSN, BNSc, SCM, SRN, Department of Nursing, Faculty of Medicine, University Kebangsaan Malaysia Medical Centre (UKMMC), Jalan Yaacob Latiff, Cheras 54000, Kuala Lumpur. Email: jalinakarim@ hotmail.com

\section{Introduction}

Education of health professionals should use a variety of appropriate teaching and learning strategies in order to help students achieve learning outcomes that include appropriate knowledge, psychomotor skills, and professional attitudes (1). A variety of teaching strategies will prepare students to practice successfully in real working environment. The quality of learning depends on the motivation and creativity which are used to enhance the process of students learning. As stated in the CAIPE definition: "IPE occurs when two or more professions learn with, from and about each other to improve collaboration and the quality of care" $(2,3)$.

IPL is now an essential part of health professional education and has been introduced in many countries (3). In order to deliver 
effective health care services, interprofessional collaboration should be introduced to students during their pre-registration/licensure studies ( 5 , 6) which will prepare them to work collaboratively after they graduate (3). IPL is a way to facilitate collaboration among health professional teams, and will help nursing students learn with, from and about other health professionals, to achieve this goal.

IPL addresses various factors that are common in practice, such as, team based patient care and collaborative practice (6). It is inappropriate for members of a health care team to work independently if their goal is high quality care. It is therefore a necessary that each team member learns to work together in order to achieve patient oriented goals $(7,8)$. To ensure nursing students collaborate with other health professionals, they must be provided with active educational and learning opportunities to improve their understanding of other health professionals (9).

Currently, nursing students are taught to focus on their specific professional roles (10) and are unable to learn together during their clinical training due to professional boundaries imposed, for example, by scopes of practice, regulation and accreditation. There is a clear need to make innovations in teaching, especially during clinical training, in order to prepare future nurses for collaborative practice with other health professionals (11).

The objective of this study was to identify the readiness for IPL among nursing students, with the ultimate aim of providing useful information for curriculum change, and development.

\section{Method}

We conducted this study using focus group discussions. According to Lapan (12), a focus group is an interview with multiple informants (five to ten participants) the aim of which is to gather in depth information about specific topics set out in a series of focused questions. During discussion, participants are able to share their ideas and understanding on the topic discussed, thereby providing rich data (13). Our focus group comprised eight third year nursing students at UKMMC. The intention of the focus group was to gather as many responses from the participants, as possible (14). A semi- structured guide was used during the session, which focused on: 1) the knowledge, experiences and benefit that could be learned together, and 2) the possible timing of IPL during preregistration/licensing years. Discussions lasted between 45 minutes and one hour. Data captured the narrative voices from participants during the session. Prior ethical approval was obtained from the institutional ethical committee. Information sheets were provided and informed consent obtained prior to focus group discussion. Participants were assured of confidentiality.

\section{Method of Analysis}

Using thematic analysis focus group discussions were analysed manually, in four stages:

1. Transcription of the discussion was carried out by the researcher. Transcribing familiarized her with the entire text of the focus group discussions.

2. Following familiarization with the texts, the researcher carefully read the transcriptions, line by line, and performed content analysis . The content analysis described what she had interpreted in the texts.

3. The content analyses were then grouped together into themes.

4. Four major themes were derived from this grouping. The major themes best describe nursing students' knowledge and perception of IPL. Texts were shared with a colleague to check for accuracy of transcription.

\section{Results}

Data were analysed and yielded the following four themes about knowledge and perception of IPL:

- Learning with, from and about other health professionals,

- Communication skills,

- Teamwork,

- Future preparation. 
Learning with, from and about other health professionals was agreed on by a majority of participants. One commented:

'I agree that we should learn together with other professions... for example, we should learn skills on suction to the patient together with physiotherapy students... so that we can share information etc.' (Student 1)

Another student,

'... we can learn together, we would not feel awkward to share ideas, therefore, there is no gap with the medical students.' (Student 2)

'No overlap roles because everybody can participate and knows their roles during the patient managemen.t' (Student 3)

'We can learn through this experience, it can prepare us to work together in the future.'(Student 8)

The students tried to defend their roles as did mention by one of them, 'We can learn together, however, some of the professions still thinking that we have to follow orders and no autonomy during patient management.' (Student 3 )

\section{Communication skills}

Most participants mentioned that communication with other professions is important; however, they were not given a chance to communicate during patient management, as illustrate by the comment of one participant;

'At the moment we are not taught to communicate with other professions, it depends on our own initiative...'(Student 4)

As indicated above, most of the health professional education takes place within their programmes and the curricula did not emphasize on interaction with other health care professions (15) .

One participant emphasized that; 'At last patient will suffer from the miscommunication between the team.' (Student 3)

\section{Teamwork}

Teamwork was another important issue agreed on by a majority of the participants 'We need to have teamwork with students from other professionals'. One commented that 'we need the teamwork in order to deliver a quality of care to the patient.' (Student 4)

\section{The future preparation}

Participants made some specific suggestions concerning future preparation as a strategy that could help to develop IPL. For example,

1. An issue raised by a number of participants related to the number of students per group. The hope was expressed that the number of participants in a group should not be too large, and that there should be equality between the numbers of students from each profession.

2. There was concern that IPL should not be dominated by certain program. 'Need to have an equal chance to other professions involved, therefore, we can discuss the patient management easily.' (Student 7)

3. Equality was raised by some of the participants, especially in terms of assessment; "have to make sure that if an assessment is needed, the students from other professions have to do the same, so that everybody has to be responsible.' (Student 3)

4. A majority of focus group participants were favourably inclined to having topics discussed that related to their clinical training in order for them to practice in delivering a quality care to patients; 'the topic must relate to clinical placement'.

5. Some individuals mentioned that there was a, 'Need (for) a trained facilitator in the learning session and from other health professional disciplines.' (Student 4 and 5)

6. A majority of discussants agreed on exposure early to IPL. One participant said: 'It is good to expose us early to other professions, therefore, we will understand better about other professions'. In contrast, there was one participant disagreed that the students should be exposed as early as year one, as she mentioned that 'each students must be exposed to their own profession, get 
to know their profession before they can contribute to others.' (Student 3)

\section{Discussion}

The objective of this study was to identify the readiness for IPL among nursing students, with the ultimate aim of providing useful information for curriculum change, and perception of interprofessional learning.

Nursing students appear positive and ready for IPL $(4,15)$. Understanding of their own, and other health professionals' roles in managing patient care increased after students had been exposed to IPL (5). Furthermore, uniprofessional care is seen as not being as of high quality as that provided by interprofessional teams. $(8,14)$.

There are only a few opportunities to expose students so that they understand each other roles (15) and are able to collaborate with other health professionals (7). The opportunity to learn together can break down negative feeling towards other health professionals (17). In addition, IPL is seen to improve communication skills, professional interdependence and confidence levels (16).

We also found that the majority of students in this study perceived that it is good to expose them early to IPL. Based on findings by Priest and Robert (18), it is essential to expose students early in order that they become effective collaborative team members. Early exposure is seen as encouraging the development of positive attitudes and behaviours (19). However, it is also possible that it is not good to expose students to IPL too early since they may not yet be familiar with their own professional roles which might negatively impact their contribution to team learning $(7,20)$.

Steinert (17) argued that early exposure to IPL can give students chance to actively participate in collaborative patient care and therefore develop positive attitudes to working together with other health professionals at an early stage in their education (7). In addition, the discussants highlighted issues such as assessment. It is clear that IPL should be accurately assessed since it is known that objective and fair assessment motivates students to learn (7).

From discussion in the focus groups, it was clear that there is a need for experienced facilitators to facilitate IPL. Experienced and committed facilitators are required to be involved in IPL (7) from different disciplines $(16,20)$. Facilitators who are poorly prepared and unable to become a good role models will clearly interfere with the success of the IPL (17).

The number of students and equal representation across programs are seen as important factors for the success of IPL and both were mentioned by a majority of students. IPL requires a small learning group (7) between 5-10 students (22). The number of students from each profession must be equal in order to experience good interprofessional interactions (19) and avoid domination by a large professional group (7) .

IPL is very challenging (20), it is a hard goal to achieve (22) and needs to be very carefully planned in order to avoid frictions(19) and interprofessional conflict (7). Faculty members play an important role in supporting IPL as role models. (19). Positive learning environments, which encourage socialization, should be supported as students will then give their full commitment to IPL (17). There will be challenges in designing and implementing the IPE (15). Good planning, designing and preparation for the difficulties that could arise (18) such as scheduling, number of students and accountability (22) will end with the success(7). Changing and developing curriculum that facilitates IPL is known to ensure that high quality patient care is the outcome of health professional education.

\section{Conclusion}

In this study, responses of focus group participants showed that IPL is perceived as positive in terms of interest, acceptance and understanding. This study also showed that nursing students are ready for a curriculum that 
embraces IPL. This idea has significant potential for the future of nursing education. It is suggested that IPL can be introduced and implement and it is an opportunity for nursing students to learn how to work collaboratively with other health professionals. Giving these findings, there is a clear need to examine best methods for introducing IPL into nursing curriculum. The suggestions and opinions of focus group discussants with respect to preparing a future IPL module are viewed as positive in assisting curriculum development. Findings from this study will support those responsible for the development of nursing curricula to include interprofessional learning and collaborative practice as a goal to high quality and safe patient care.

\section{Reference}

1. Nabishah M. Cabaran Pendidikan Perubatan abad ke 21. Universiti Kebangsaan Malaysia; 2011.

2. CAIPE. Centre for the Advancement of Interprofessional Education [Internet]. 2002. Available from: http://www.caipe.org.uk/resources/definingipe/

3. Coster S, Norman I, Murrells T, Kitchen S, Meerabeau E, Sooboodoo E, et al. Interprofessional attitudes amongst undergraduate students in the health professions: a longitudinal questionnaire survey. Int J Nurs Stud. 2008 Nov;45(11):1667-81.

4. D'Amour D, Ferrada-Videla M, San Martin Rodriguez L, Beaulieu M-D. The conceptual basis for interprofessional collaboration: core concepts and theoretical frameworks. J Interprof Care. 2005 May;19 Suppl 1(May):116-31.

5. Hylin U, Lonka K, Ponzer S. Students approaches to learning in clinical interprofessional context. Med Teach. 2011;33:e204-e210.

6. Sargeant J. Theories to Aid Understanding and Implementation of Interprofessional Education. J Contin Educ Health Prof. 2009;29(3):178-84.
7. Begley CM. Developing inter-professional learning: tactics, teamwork and talk. Nurse Educ Today; 2009 Apr;29(3):276-83.

8. Reeves, S., Lewin, S., Espin, S., Zwarenstein M. Promoting Partnership for health. Interprofessional Teamwork for Health and social care. Wiley-Blackwell.UK; 2010.

9. Rothgeb MK. Creating a nursing simulation laboratory: a literature review. J Nurs Educ. 2008 Nov;47(11):489-94.

10. Lumague M, Morgan A, Mak D, Hanna M, Kwong J, Cameron C, et al. Interprofessional education: the student perspective. J Interprof Care. 2006 Jun;20(3):246-53.

11. Cody WK. Interdisciplinarity and Nursing: "Everything is Everything," or Is It? Nurs Sci Q. 2001 Oct 1;14(4):274-80.

12.Lapan SD, Quartaroli MT. Qualitative Research An Introduction to Methods and Designs. Riemer FJ, editor. Jossey-Bass; 2012.

13. Goodman C, Evans C. Using Focus Groups. In: Gerrish K, Lacey A, editors. The research process in nursing. UK: Blackwell Publishing; 2006. p. 550.

14.Stewart, D.W., Shamsadani, P.N., Rook. DW. Focus groups theory and practice. 2nd ed. Sage publication.USA.; 2007.

15. Barnsteiner JH, Disch JM, Hall L, Mayer D, Moore SM. Promoting interprofessional education. Nurs Outlook. 2007;55(3):144-50.

16. Street KN, Eaton N, Clarke B, Ellis M, Young PM, Hunt L, et al. Child disability case studies: an interprofessional learning opportunity for medical students and paediatric nursing students. Med Educ. 2007 Aug;41(8):771-80.

17. Steinert Y. Learning together to teach together: interprofessional education and faculty development. J Interprof Care. 2005 May;19 Suppl 1(May):60-75.

18.Priest, H.M., Robert, P. DH. Interprofessional education and working in mental health: in search of the evidence based. J Nurs Manag. 2008;16(4):474-85.

19.Oandasan I, Reeves S. Key elements for interprofessional education. Part 1: the learner, the educator and the learning context. J Interprof Care. 2005 May;19 Suppl 1(May):21-38. 
20. Ker J, Mole L, Bradley P. Early introduction to interprofessional learning: a simulated ward environment. Med Educ. 2003 Mar;37(3):248-55.

21. Hammick M, Freeth D, Koppel I, Reeves S, Barr H. A best evidence systematic review of interprofessional education: BEME Guide no. 9. Med Teach. 2007 Oct;29(8):735-51.

22. Freeth D, Nicol M. Learning clinical skills: an interprofessional approach. Nurse Educ Today. 1998 Aug;18(6):455-61.

\section{Appendix}

\section{Semi structured questionnaire}

1. How far do you feel your achievement in the learning process?

2. Have you ever heard about Interprofessional Learning (IPL)?

3. Do you know about IPL in general or our faculty?

4. Do IPL been practicing in our faculty?

5. What are the advantages of IPL that you know?

5. If there will be a new learning package that involves the IPL, what do you aspect from this learning package? 